\title{
Hydrogen Sulfide Signaling in Oxidative Stress and Aging Development
}

\author{
Guangdong Yang, ${ }^{1}$ Steven S. An, ${ }^{2}$ Yong Ji, ${ }^{3}$ Weihua Zhang, ${ }^{4}$ and Yanxi Pei ${ }^{5}$ \\ ${ }^{1}$ School of Kinesiology, Lakehead University, Thunder Bay, Canada P7B 5E1 \\ ${ }^{2}$ Department of Environmental Health Sciences, Bloomberg School of Public Health, Johns Hopkins University, \\ Baltimore, MD 21218, USA \\ ${ }^{3}$ Department of Pathophysiology, Nanjing Medical University, Nanjing 210029, China \\ ${ }^{4}$ Department of Pathophysiology, Harbin Medical University, Harbin 150081, China \\ ${ }^{5}$ School of Life Science, Shanxi University, Taiyuan 030006, China \\ Correspondence should be addressed to Guangdong Yang; gyang@lakeheadu.ca
}

Received 31 March 2015; Accepted 31 March 2015

Copyright (C) 2015 Guangdong Yang et al. This is an open access article distributed under the Creative Commons Attribution License, which permits unrestricted use, distribution, and reproduction in any medium, provided the original work is properly cited.

Just in the last decade, the knowledge of the physiologic functions of hydrogen sulfide $\left(\mathrm{H}_{2} \mathrm{~S}\right)$ in medicine and biology has been tremendously accumulated [1-3]. $\mathrm{H}_{2} \mathrm{~S}$ has emerged to be one important member of the family of gasotransmitters, together with nitric oxide (NO) and carbon monoxide (CO) $[1,2]$. The ubiquitous distribution of $\mathrm{H}_{2} \mathrm{~S}$-producing enzymes and the potent chemical reactivities of $\mathrm{H}_{2} \mathrm{~S}$ in biological system make this molecule unique in regulating cellular and organ functions in both the mammalian and plants [13]. Pathophysiological abnormalities related to altered $\mathrm{H}_{2} \mathrm{~S}$ metabolism and function have been demonstrated in many cases $[2,3] . \mathrm{H}_{2} \mathrm{~S}$ possesses a great therapeutic potential in ageassociated diseases by modulation of oxidative stress $[4,5]$.

This special issue contains review paper and research articles that focus on the topics of $\mathrm{H}_{2} \mathrm{~S}$ signaling in oxidative stress and aging development, including discussions on the potency and efficiency of $\mathrm{H}_{2} \mathrm{~S}$ in dealing with various diseases. A number of contributions have addressed the protective role of $\mathrm{H}_{2} \mathrm{~S}$ in cardiovascular diseases and diabetes. In an original research article, $\mathrm{H}$. Yu et al. demonstrate that $\mathrm{H}_{2} \mathrm{~S}$ decreases NADPH oxidase activity and reactive oxidative species (ROS) production, which lead to reduced mean arterial pressure and heart rate in spontaneously hypertensive rats. $\mathrm{H}_{2} \mathrm{~S}$, as an antioxidant, may be a potential target for cardiovascular diseases. A research article by $\mathrm{S}$. Jin and colleagues compares $\mathrm{H}_{2} \mathrm{~S}$ generation in ageing diabetic mouse hearts, and they find that $\mathrm{H}_{2} \mathrm{~S}$ levels are reduced in the diabetic heart due to the alterations in $\mathrm{H}_{2} \mathrm{~S}$-producing enzymes, which might be related with the pathogenesis of diabetic cardiomyopathy. Y. Zong and colleagues explore the possible effects of endogenous $\mathrm{H}_{2} \mathrm{~S}$ on endothelial apoptosis under high-salt stimulation, and their data validate that supplementation of $\mathrm{H}_{2} \mathrm{~S}$ donor markedly inhibits vascular endothelial cell oxidative stress and mitochondria-related apoptosis induced by high salt. Q. Wang and colleagues report that $\mathrm{H}_{2} \mathrm{~S}$ antagonizes advanced glycation end-products induced-epithelial sodium channel activity by targeting the ROS/PI3K/PTEN pathway in A6 cells. The authors conclude that $\mathrm{H}_{2} \mathrm{~S}$ may provide protection against hypertension in diabetic patients. In a review paper by $\mathrm{Y}$. Shen and colleagues, the underlying mechanisms for the cardioprotective effects of $\mathrm{H}_{2} \mathrm{~S}$ against myocardial infarction, arrhythmia, hypertrophy, heart failure, and so forth are discussed. Some mechanisms, including antioxidative action, preservation of mitochondrial function, reduction of apoptosis, anti-inflammatory responses, angiogenic actions, regulation of ion channel, and interaction with $\mathrm{NO}$, are mostly responsible for the cardioprotective effect of $\mathrm{H}_{2} \mathrm{~S}$.

Some papers in this special issue describe new insights into the therapeutic potential in fibrosis. In a review paper, S. Zhang and colleagues summarize studies that supplement with exogenous $\mathrm{H}_{2} \mathrm{~S}$ mitigates the severity of fibrosis in 
various experimental animal models. The protective role of $\mathrm{H}_{2} \mathrm{~S}$ in the development of fibrosis is primarily attributed to its antioxidation, antiapoptosis, anti-inflammation, proangiogenesis, and inhibition of fibroblasts activities. K. Song and colleagues continue on with this topic that $\mathrm{H}_{2} \mathrm{~S}$ protects fibrosis diseases that relate to heart, liver, kidney, and other organs. In a research article, G. Meng and colleagues provide new evidence on the protective role of GYY4137, a slowreleasing $\mathrm{H}_{2} \mathrm{~S}$ donor, in myocardial fibrosis by inhibiting oxidative stress, blocking TGF- $\beta 1 / \mathrm{Smad} 2$ signaling pathway, and decreasing in expression of $\alpha$-SMA. Further clinical studies are needed to translate this potential to clinical use.

$\mathrm{D}$. $\mathrm{Wu}$ and colleagues highlight the recent findings regarding the role of $\mathrm{H}_{2} \mathrm{~S}$ in ischemia-reperfusion (I/R) injury. In their paper, the authors proposed that treatment with $\mathrm{H}_{2} \mathrm{~S}$ or its donors in proper dose range and time frame will exhibit more potent therapeutic effects against I/R injury in further preclinical research and clinical application. A review article by $\mathrm{W}$. Zhang and her colleagues addresses the reciprocal interaction between $\mathrm{H}_{2} \mathrm{~S}$ and calcium ion channels and transporters through different mechanisms, all of which are essential for the maintenance of intracellular calcium homeostasis by $\mathrm{H}_{2} \mathrm{~S}$. In an original research article, L. Zhang and colleagues explore the role of $\mathrm{H}_{2} \mathrm{~S}$ in human gastric neoplasias. Their data point that $\mathrm{H}_{2} \mathrm{~S}$ level is lower in noncancerous gastric samples in comparison with human gastric carcinoma mucosa, and the authors further prove that $\mathrm{H}_{2} \mathrm{~S}$ induces apoptosis and inhibits cell migration and invasion of gastric cancer cells by regulating apoptosis related proteins. The therapeutic application of $\mathrm{H}_{2} \mathrm{~S}$ donors against gastric cancer development can be realized.

In a review article, $\mathrm{B}$. Wu and colleagues discuss the latest research on the interaction of $\mathrm{H}_{2} \mathrm{~S}$ with oxygen sensing under hypoxia condition. Emerging evidence has elucidated an important protective role of $\mathrm{H}_{2} \mathrm{~S}$ in hypoxia-mediated damage in many mammalian systems. By regulating the functions of hypoxia-inducible factors and the activation of carotid bodies, $\mathrm{H}_{2} \mathrm{~S}$ acts as important oxygen/hypoxia sensor.

Not only has it acted as a signalling molecule in mammalian system, but also overwhelming evidence has demonstrated that $\mathrm{H}_{2} \mathrm{~S}$ plays important roles in diverse physiological processes in plants. J. Zhu and Y. Pei discuss in a review article the physiological implications of $\mathrm{H}_{2} \mathrm{~S}$ in plants. $\mathrm{H}_{2} \mathrm{~S}$ modulates various defence responses in plants, including growth and development, abiotic stress, heavy metal toxicity, drought and osmotic stress, hypoxia, senescence, and maturation by interacting with plant hormones, hydrogen peroxide, NO, $\mathrm{CO}$, and other molecules. The same research group also provides evidence that $\mathrm{H}_{2} \mathrm{~S}$ alleviates cadmium-induced cell death in Chinese cabbage roots, and they further verify that, by upregulating antioxidant enzyme activities, $\mathrm{H}_{2} \mathrm{~S}$ removes excessive ROS and reduces cell oxidative damage induced by cadmium. In one original research article, Y. Zhang and colleagues demonstrate that $\mathrm{H}_{2} \mathrm{~S}$ acts as an antioxidant in delaying cell apoptosis and enhancing $\alpha$-amylase secretion regardless of the presence of gibberellic acid in barley aleurone layers. In addition, D.-B. Zhu and colleagues investigate the effects of $\mathrm{SO}_{2}$ pretreatment on $\mathrm{H}_{2} \mathrm{~S}$ and ROS accumulation in germinating wheat seeds, and their data suggest that
$\mathrm{SO}_{2}$ could increase endogenous $\mathrm{H}_{2} \mathrm{~S}$ accumulation and the antioxidant capability and decrease endogenous aluminum content in wheat grain to alleviate aluminum stress. $\mathrm{SO}_{2}$ may be reduced to $\mathrm{H}_{2} \mathrm{~S}$ by sulfite reductase, thus contributing to $\mathrm{H}_{2} \mathrm{~S}$ production.

The articles presented in this special issue highlight the current advances in the research field of $\mathrm{H}_{2} \mathrm{~S}$ in medicine and biology. These articles not only enrich our understanding of how $\mathrm{H}_{2} \mathrm{~S}$ regulation of oxidative stress in various disorders occurs but also provide evidence on the therapeutic potential of $\mathrm{H}_{2} \mathrm{~S}$ against aging development and other disorders. We hope that readers will find these contributions interesting and informative.

\section{Acknowledgments}

We would like to thank the reviewers for their expert assistance and all authors for the contribution to this issue. We would greatly appreciate funding from US National Heart, Lung, and Blood Institute, Grant HL107361.

Guangdong Yang
Steven S. An
Yong Ji
Weihua Zhang
Yanxi Pei

\section{References}

[1] R. Wang, "Two's company, three's a crowd: can $\mathrm{H}_{2} \mathrm{~S}$ be the third endogenous gaseous transmitter?" The FASEB Journal, vol. 16, no. 13, pp. 1792-1798, 2002.

[2] R. Wang, "Physiological implications of hydrogen sulfide: a whiff exploration that blossomed," Physiological Reviews, vol. 92, no. 2, pp. 791-896, 2012.

[3] R. Wang, "Gasotransmitters: growing pains and joys," Trends in Biochemical Sciences, vol. 39, no. 5, pp. 227-232, 2014.

[4] Y. Ju, W. Zhang, Y. Pei, and G. Yang, " $\mathrm{H}_{2} \mathrm{~S}$ signaling in redox regulation of cellular functions," Canadian Journal of Physiology and Pharmacology, vol. 91, no. 1, pp. 8-14, 2013.

[5] B. Qabazard, L. Li, J. Gruber et al., "Hydrogen sulfide is an endogenous regulator of aging in Caenorhabditis elegans," Antioxidants \& Redox Signaling, vol. 20, no. 16, pp. 2621-2630, 2014. 


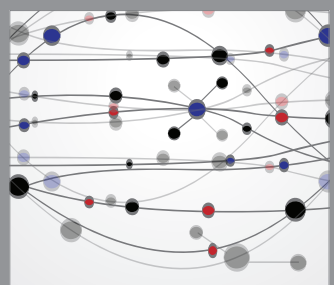

The Scientific World Journal
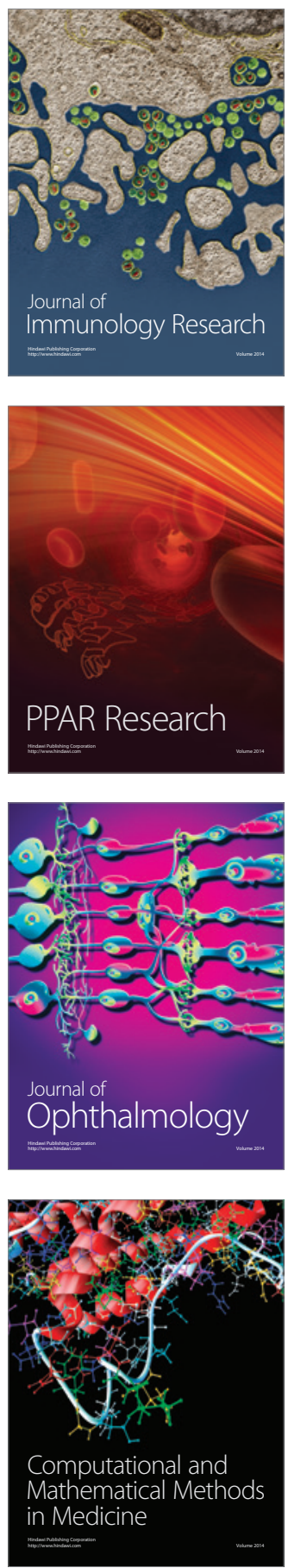

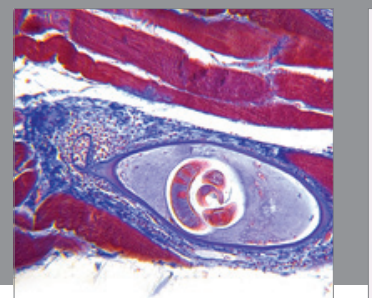

Gastroenterology

Research and Practice
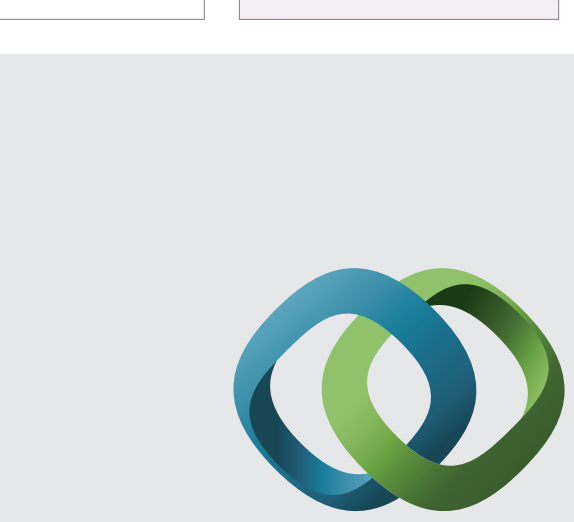

\section{Hindawi}

Submit your manuscripts at

http://www.hindawi.com
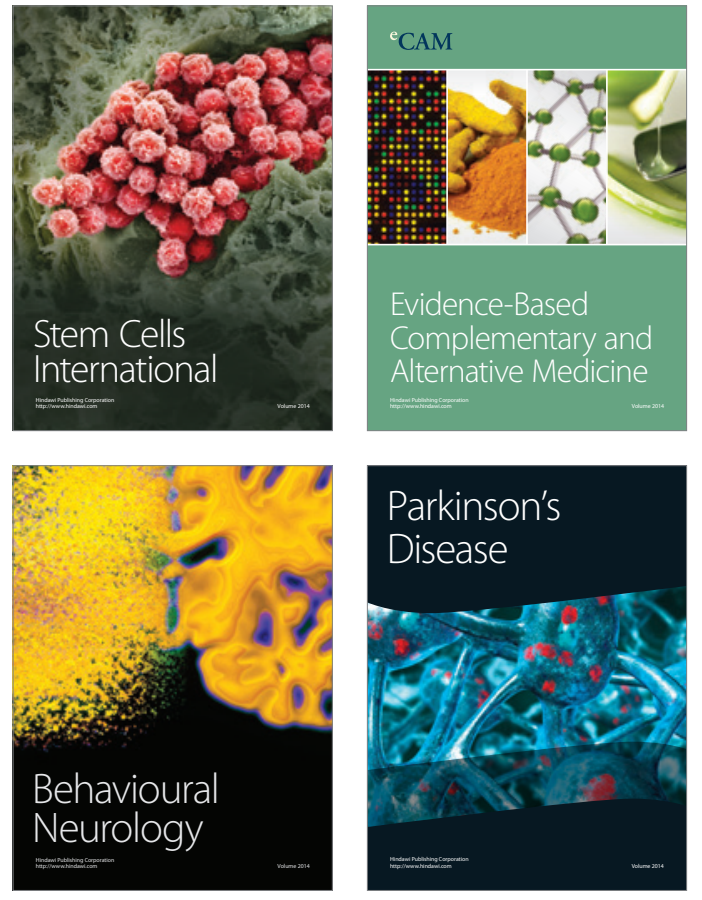
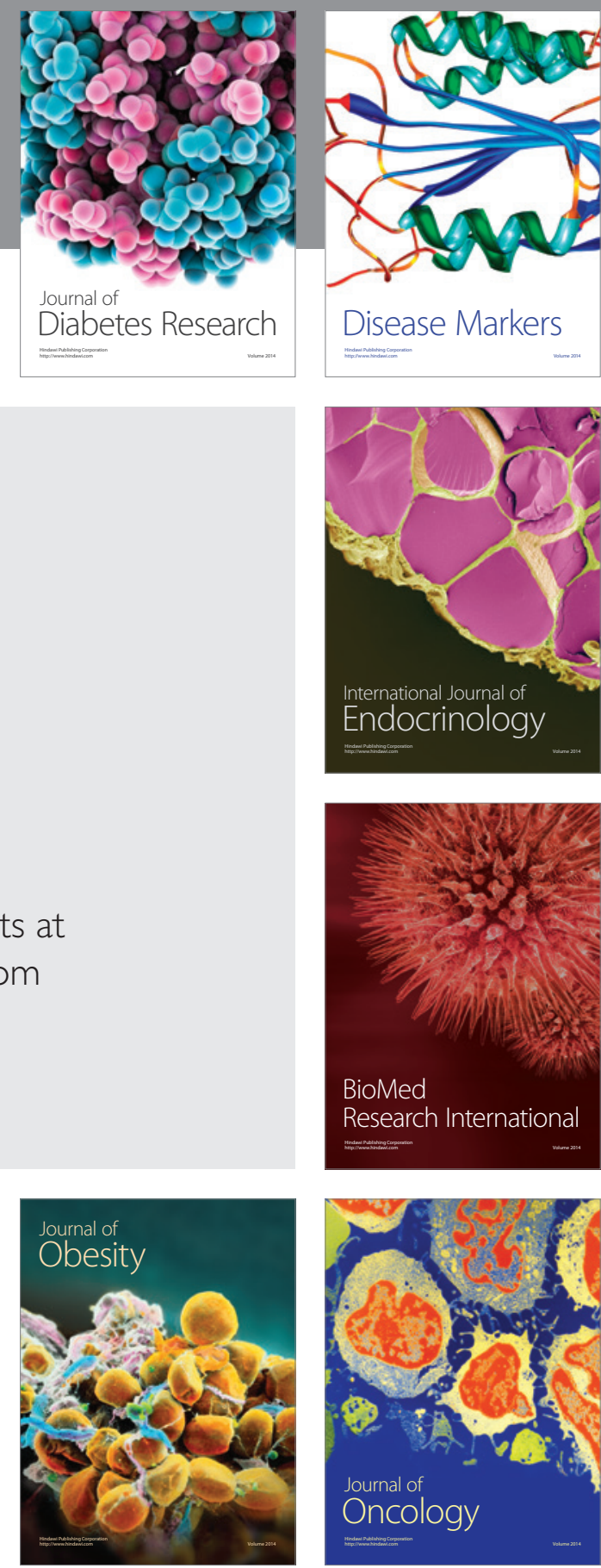

Disease Markers
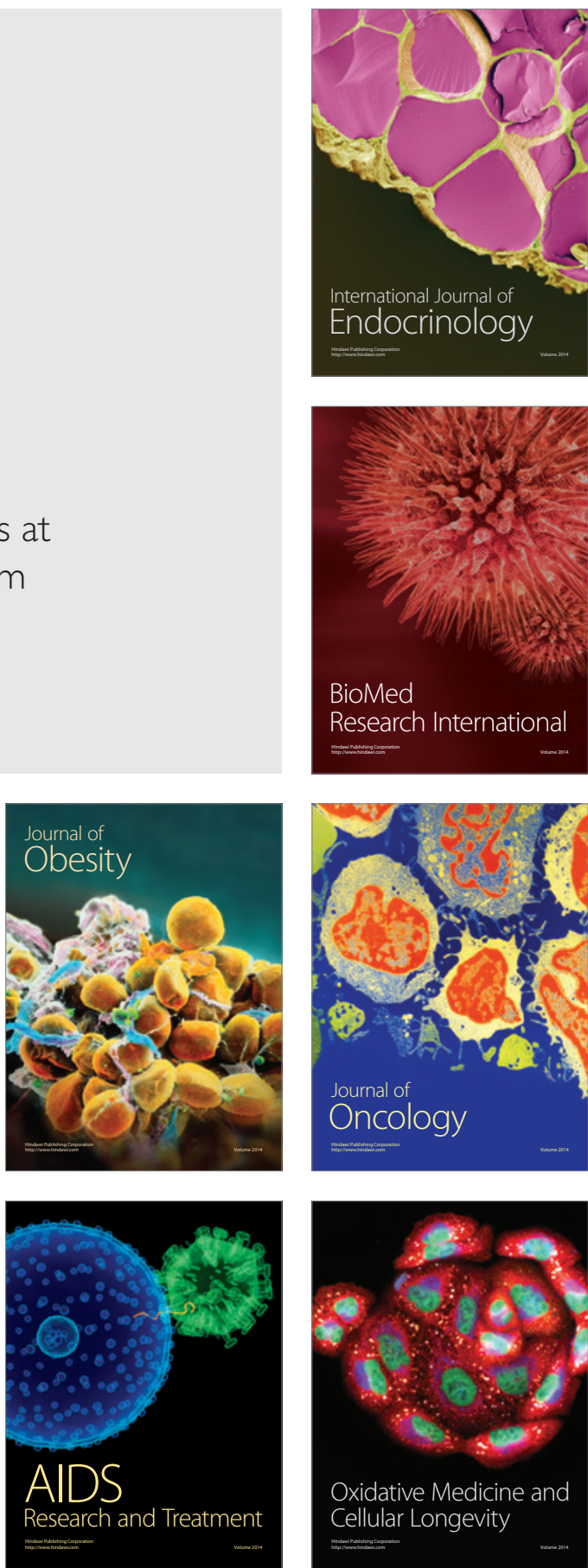